\title{
COMPARAÇÃO ENTRE USO DE ÁGUA EM PLANTAÇÕES DE Eucalyptus grandis E FLORESTA OMBRÓFILA DENSA (MATA ATLÂNTICA) NA COSTA LESTE DO BRASIL ${ }^{1}$
}

\author{
Auro Campi de Almeida² e João Vianei Soares ${ }^{3}$
}

\begin{abstract}
RESUMO - Existe uma controvérsia histórica sobre o uso de água em plantações de eucalipto em vários países onde estas plantações vêm se expandindo. Este trabalho apresenta os resultados de um monitoramento hidrológico intensivo que vem sendo realizado desde 1994 em uma microbacia no município de Aracruz-ES, Brasil. As medições realizadas nos plantios de eucalipto (Eucalyptus grandis W. Hill ex Maiden) e em uma floresta nativa (Mata Atlântica) e as estimativas a partir de modelos hidrológicos para o cálculo de balanço hídrico demonstram que as plantações de eucalipto se comparam à floresta nativa quanto à evapotranspiração anual e ao uso de água do solo. Considerando o ciclo de crescimento do eucalipto para produção de celulose, o uso de água pela plantação pode ser inferior ao da floresta nativa, principalmente no início do ciclo. A análise da relação entre evapotranspiração e precipitação mostrou que em anos em que a precipitação é próxima à média anual existe um equilíbrio entre a perda e a entrada de água através da precipitação pluviométrica.
\end{abstract}

Palavras-chave: Eucalipto, Mata Atlântica, uso de água, modelos hidrológicos, balanço hídrico e evapotranspiração.

\section{COMPARISON OF WATER USE IN Eucalyptus grandis PLANTATIONS AND ATLANTIC RAINFOREST IN EASTERN COAST OF BRAZIL}

\begin{abstract}
A historical controversy exists on the use of water by eucalypt plantations worldwide. This study presents the results of an intensive hydrologic monitoring carried out since 1994 in a watershed in Aracruz-ES, Brazil. After over eight years of measuring a eucalyptus forest and its neighboring native species stands (Atlantic Rainforest), the measurements and hydrological models have shown that the eucalypt trees may consume water more economically than the native trees, considering its whole growing cycle of seven years. The evapotranspiration and precipitation ratio showed a water balance when the precipitation is close to the annual average.
\end{abstract}

Key words: Eucalypt, Atlantic rainforest, water use, hydrologic models, water balance, evapotranspiration.

\section{INTRODUÇÃO}

A hidrologia florestal trata do movimento da água em ambientes de floresta, sejam naturais ou de plantações de espécies de crescimento rápido. O balanço de água nestes ambientes depende da precipitação, da interceptação de água pelo dossel, do escoamento lateral e em profundidade (drenagem profunda) e da evapotranspiração. Com exceção da precipitação, os demais processos são bastante influenciados pela densidade de plantas, pelo tipo de solo, pelo comportamento fisiológico da planta e pela estrutura e arquitetura do dossel.

1 Recebido para publicação em 12.11.2002.

Aceito para publicação em 19.2.2003.

2 Aracruz Celulose S.A., Rodovia Aracruz/Barra do Riacho, 29192-000 Aracruz-ES, Brasil, Tel. +55 2732702676 , fax +55 273270 2689, <aca@aracruz.com.br>. ${ }^{3}$ Instituto de Pesquisas Espaciais, Avenida dos Astronautas 1758, $12227-010$ São José dos Campos-SP, Brasil, < vianei@ltid.inpe.br>. 
No Brasil o plantio florestal tem aumentado nos últimos 20 anos, ocupando uma área de 4,8 milhões de hectares em 2000, sendo 3,0 milhões de hectares de eucalipto $(6,14 \%)$ e 1,8 milhão de pinus (3,68\%). Destes, 65\% estão concentrados nos Estados de Minas Gerais, Paraná e São Paulo, ocupando apenas 4,64\% da área total destes Estados (SBS, 2001). O Espírito Santo, onde foi desenvolvido este estudo, possui um total de 152.330 ha de plantações de eucalipto (SBS, 2001), ocupando 3,3\% da área total do Estado (IBGE, 2002).

Existe uma controvérsia histórica sobre o papel desempenhado pelo eucalipto com relação ao uso e à disponibilidade de água das bacias de drenagem onde são plantados. Duas questões freqüentemente abordadas são a crença de que o eucalipto provoca rápido secamento do solo e as perdas de biodiversidade ecológica em relação ao ecossistema original. $\mathrm{O}$ crescimento rápido das plantações de eucalipto na costa atlântica dos Estados do Espírito Santo e da Bahia, de clima tropical ( $A_{f}$ na classificação de Köppen) e tropical de savana $\left(A_{w}\right)$, sustenta a associação entre cobertura vegetal e disponibilidade de água. A classificação clássica de Köppen usa a vegetação natural como uma expressão do clima, além da temperatura, da chuva e das características sazonais. O ecossistema original dessa região é a Floresta Ombrófila Densa (Mata Atlântica), fisionomia associada ao clima $A_{f}$. A Mata Atlântica apresenta extrema riqueza em biodiversidade e merece também ser estudada, considerando sua importância hidrológica, devendo, então, ser comparada com plantios de eucaliptos. O melhor entendimento desta questão deverá permitir que se possa tratar, com maior embasamento científico, os impactos hidrológicos e ambientais das plantações de eucaliptos no País.

O manejo integrado em bacias hidrográficas, incluindo a plantação de eucalipto e a manutenção dos remanescentes de Mata Atlântica, concentrada nas áreas de maior declividade, é uma forma de preservar a biodiversidade, além de proteger o solo contra erosão (Hewllet, 1982). Sob a óptica das práticas de manejo florestal, é necessário entender como os dois sistemas se comparam em relação ao uso da água de uma mesma bacia hidrográfica.

Soares \& Almeida (2001) desenvolveram um modelo de uso de água em plantações de eucalipto (Eucalyptus grandis W. Hill ex Maiden) que indicou que em anos em que chove em torno da média histórica da região ( 1350 mm) existe equilíbrio entre evapotranspiração e precipitação. Os autores também verificaram que o

R. Árvore, Viçosa-MG, v.27, n.2, p.159-170, 2003 eucalipto exerce controle estomático eficiente sobre a transpiração durante a estação seca. Uma versão do modelo foi também adaptada para a floresta nativa, assumindo uma parametrização compatível com a da Floresta Amazônica (Roberts et al., 1996; Sommer et al., 2002). Os objetivos deste trabalho foram quantificar e comparar o uso de água em um sistema de floresta nativa da Mata Atlântica ao de um plantio de Eucalyptus grandis para vários anos hidrológicos, considerando as plantações em diferentes estádios de crescimento.

\section{MATERIAL E MÉTODOS}

Para permitir a quantificação do uso de água nos ambientes de plantio de eucalipto e na floresta nativa, foram realizadas medições específicas de componentes do ciclo de água no sistema solo-planta-atmosfera ao longo de sete anos (de 1995 a 2001) e desenvolvidos e validados modelos de processos para estimar o balanço hídrico tanto na Mata Atlântica como nas plantações de eucalipto (Figura 1), considerando diferentes fases do ciclo produtivo (idades) das plantações. O modelo de uso de água em plantações de eucalipto (UAPE) e uma versão modificada para a floresta nativa (FloNa) foram usados para estimativa dos balanços de água no solo nos dois sistemas. Será apresentada, a seguir uma descrição simplificada dos modelos.

\section{O Modelo UAPE}

O modelo calcula diariamente o balanço de água na camada de solo que abriga o sistema radicular. Neste balanço, a água armazenada no perfil do solo (até a profundidade de exploração pelo sistema radicular) ao final do dia (i) é dada pelo estoque do dia anterior (i-1), somada da entrada (precipitação - interceptação, $P$-Icp) e subtraída da saída (transpiração + evaporação do solo+ escoamento líquido para fora do sistema, $E_{t}+E_{s}+Q_{\text {liq }}$ ):

$\Delta \theta=\theta_{\text {solo }}(i)-\theta_{\text {solo }}(i-1)=(P-I c p)-\left(E_{t}+E_{s}+Q_{\text {liq }}\right)$

em que $\theta_{\text {solo }}=\sum \theta_{v} \Delta z$, isto é, a soma em milímetros de água para as várias camadas do solo em que se mede umidade do solo, até a profundidade do sistema radicular considerado. $Q_{\text {liq }}$ é o balanço de água na interface do sistema radicular com uma camada de solo mais profunda, entre fluxo ascendente (vertical para cima) e drenagem profunda (fluxo vertical para baixo). 


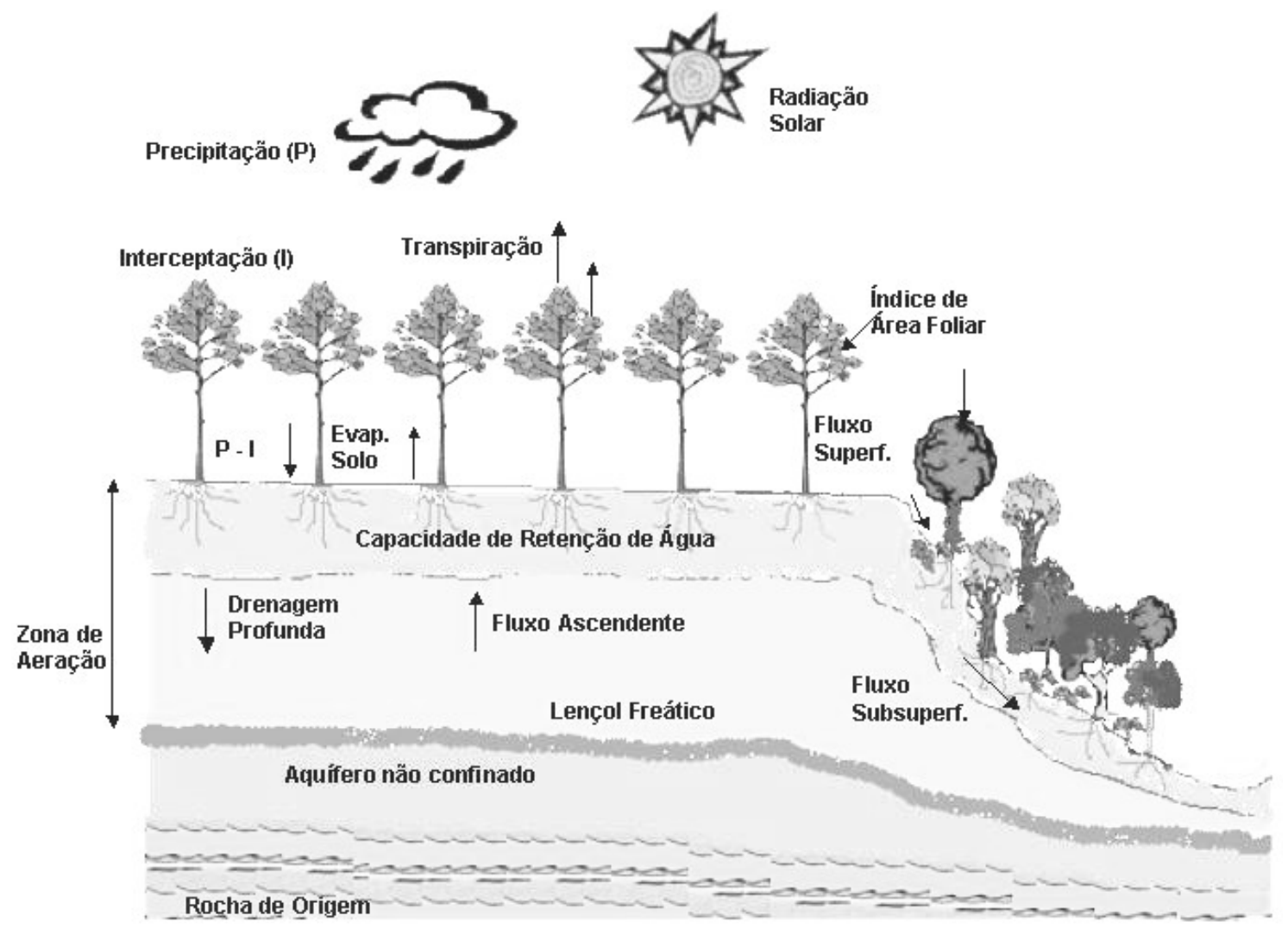

Figura 1 - Ciclo hidrológico medido na microbacia experimental da Aracruz Celulose S.A.

Figure 1 - Hydrologic cycle measured in the Aracruz Celulose S.A. experimental watershed.

A transpiração diária $(\mathrm{mm} /$ dia $)$ é estimada pela formulação clássica de Penman-Monteith, (Landsberg, 1999; Running \& Coughlan, 1988; Soares \& Almeida, 2001; Waring \& Running, 1998):

$$
E_{t}=\frac{1}{L} \cdot\left[\frac{\Delta R_{n}+\rho_{a} c_{p} g_{a} D}{(\Delta+\gamma)\left(1+g_{a} / g_{c}\right)}\right] \cdot t
$$

em que $\Delta$ é a declividade da curva de pressão de saturação de vapor $\left(\mathrm{mbar} /{ }^{\circ} \mathrm{C}\right)$; na temperatura $T ; R_{n}$ é a radiação líquida média durante o dia $\left(\mathrm{W} / \mathrm{m}^{2}\right) ; \rho_{a}$ é a densidade do $\operatorname{ar}\left(\mathrm{kg} / \mathrm{m}^{3}\right) ; \gamma$ é a constante psicrométrica $\left(\mathrm{mbar} /{ }^{\circ} \mathrm{C}\right) ; D$ é o déficit de pressão de vapor entre o ar e o dossel (mbar); $c_{p}$ é o calor específico do $\operatorname{ar}\left(\mathrm{J} / \mathrm{kg} /{ }^{\circ} \mathrm{C}\right) ; g_{a}$ é a condutância aerodinâmica do dossel $(\mathrm{m} / \mathrm{s}) ; g_{c}$ é a condutância global do dossel ao vapor d'água $(\mathrm{m} / \mathrm{s}) ; L$ é o calor latente de vaporização da água $(\mathrm{J} / \mathrm{kg})$; e $t$ é a duração do dia (em segundos, s). A condutância global do dossel, $g_{c^{\prime}}$ é dada por $g_{c}=g_{s}$. IAF, em que $g_{s}$ é a condutância estomática (convertida em unidades de $\mathrm{m} / \mathrm{s}$ ) e IAF é o índice de área foliar $\left(\mathrm{m}^{2} / \mathrm{m}^{2}\right)$.

A partir de dados de campanhas ecofisiológicas de campo (Mielke et al., 1999), foram desenvolvidas três relações funcionais:

- entre o potencial de água na folha ao amanhecer $\left(\Psi_{1}\right)$ e a disponibilidade relativa de água no solo (equação 3);

- correção de $g_{s}$ em função de $\Psi_{1}$ (equação 4); e

- uma equação de correção (redução) para o déficit de vapor d'água, $D$ (equação 5).

$$
\Psi_{1}=-0.33 \cdot\left(\frac{\theta}{\theta_{\max }}\right)^{-0.57}
$$

R. Árvore, Viçosa-MG, v.27, n.2, p.159-1 70, 2003 


$$
g_{s}=g_{s \max }-m_{w}\left(\Psi_{1}-\Psi_{1 \min }\right)
$$

em que $g_{\text {smax }}$ é a condutância máxima possível, sem déficit de água no solo quando o limiar de radiação foi atingido no início da manhã; $\Psi_{\text {lmin }}$ é o potencial de água na folha que induz ao fechamento estomático completo (em torno de $-2,0 \mathrm{MPa}$ ); e $m_{w}$ é a declividade da função, cujo valor ajustado para o eucalipto foi de $-0,7 \mathrm{~cm} / \mathrm{s} / \mathrm{MPa}$.

$$
g_{c D}=g_{c}+\left[\frac{f_{g c} \cdot g_{c}-g_{c}}{3}\right] \cdot D
$$

em que $f_{g c}$ é a fração de $g_{s}$ quando $D=3 \mathrm{KPa}$. O termo entre colchetes é a declividade da relação linear de $g_{c}$ vs. $D$. Então, $g_{c D}$ é a condutância média diária corrigida para os efeitos da água disponível no solo e do déficit de pressão de vapor.

A evaporação do solo $\left(E_{s}\right)$ é estimada pela equação de Penman-Monteith com a condutância do solo, diminuindo rapidamente à medida que a disponibilidade de água no solo cai, conforme Choudhury \& Monteith (1988) e Soares \& Almeida (2001).

Um submodelo de fluxo de água foi desenvolvido e acoplado ao modelo de balanço. O solo é dividido em várias camadas, entre as quais a água se move segundo o gradiente hidráulico (lei de Darcy). A condutividade hidráulica no perfil do solo é estimada com base na textura de solo, segundo Campbell (1974) e Clapp \& Hornberger (1978). Em períodos de seca prolongada, com a retirada de água pelo sistema radicular da primeira camada de solo, pode ocorrer inversão do gradiente de potencial total (de água no solo), com conseqüente fluxo ascendente a partir de camadas mais profundas. Uma descrição detalhada do modelo UAPE, incluindo o submodelo de fluxo de água no solo, encontra-se em Soares \& Almeida (2001).

\section{O Modelo Flona (Floresta Nativa)}

Os remanescentes de Mata Atlântica da microbacia experimental da Aracruz Celulose ocupam 30\% da área total de 286 ha e estão nos declives da drenagem da bacia. Neste ecossistema a profundidade do sistema radicular é em média bem maior que a do eucalipto, podendo atingir $5 \mathrm{~m}$ ou mais; no eucalipto na área de estudo e no final da rotação ( 7 anos) a profundidade das raízes chega a 2,5 m. Deste modo, a capacidade de retenção de água na floresta

R. Árvore, Viçosa-MG, v.27, n.2, p.159-170, 2003 nativa é superior a $400 \mathrm{~mm}$, o que torna dispensável uma compartimentalização do solo para estabelecimento de gradientes hidráulicos e movimento de água. Esta é a diferença básica em relação ao modelo de balanço para o eucalipto. As condições iniciais e os parâmetros são diferentes para os dois sistemas, pois estes apresentam índice de área foliar, $(I A F)$ diferentes e coeficientes de interceptação de chuva $(I)$ também distintos. Os valores de condutância do dossel foram estabelecidos para o eucalipto com base em experimentos específicos (Mielke et al., 1999). No caso da Mata Atlântica (Flona) assumiuse o comportamento estabelecido por McWilliam et al. (1996) e Roberts et al. (1996). Essas equações foram obtidas durante o projeto ABRACOS, em que os valores de potencial de água na folha ao amanhecer $\left(\Psi_{1}\right)$, para espécies florestais, estiveram sempre próximos de $0,5 \mathrm{MPa}$, os valores de $g_{s}$ próximos de $1 \mathrm{~cm} / \mathrm{s}$ e com uma dependência linear de $g_{s}$ em função de D muita próxima à da obtida para o eucalipto. $\mathrm{O}$ experimento de interceptação de água pelo dossel estabelecido também nos remanescentes de mata nativa da microbacia experimental permitiu o estabelecimento de seu coeficiente de interceptação, utilizado no modelo Flona. Medidas de $I A F$ foram também obtidas in situ, em ambos os ambientes.

\section{Medições Hidrometeorológicas}

A microbacia experimental (MBE) da Aracruz Celulose S.A. (Figura 2), localizada no município de Aracruz-ES (19 $\left.51^{\prime} \mathrm{S}, 40^{\circ} 14^{\prime} \mathrm{W}\right)$, foi estabelecida em 1994. A MBE possui uma área de 286 ha, dos quais 190 ha são de plantações de eucalipto e 86 ha estão cobertos por floresta nativa (Mata Atlântica) em estádio avançado e médio de regeneração; os 10 ha restantes são estradas. Essa microbacia foi escolhida com base em critérios que garantem a sua representatividade na regional que abrange cerca de 40.000 ha. Os principais fatores analisados para a escolha da microbacia foram: tipos de solos, cobertura vegetal, relação de área ocupada entre floresta nativa e plantios de eucalipto, topografia, localização, rede de drenagem e dimensões. Nas áreas de plantio de eucalipto domina a topografia plana, enquanto na de floresta nativa predomina maiores declividades. Após a seleção da área foi realizado um levantamento hidrogeológico detalhado, utilizando técnicas geofísicas, para assegurar que a bacia é um sistema fechado sem falhas geológicas, em que se assume que não há entrada ou saída de água (não-controladas) a nível subterrâneo (Albuquerque et al., 1997). Além dos estudos 
hidrológicos, a microbacia tem sido utilizada para estudos detalhados em conservação de solo, ecofisiologia, flora e fauna (avifauna e entomofauna), alocação de biomassa e crescimento das plantações de eucalipto. A Figura 2 mostra a localização da instrumentação e dos experimentos na microbacia destinados às análises hidrológicas.

Para as medidas meteorológicas foram instaladas três estações automáticas em torres acima da copa das árvores, onde se medem: precipitação pluviométrica $(\mathrm{mm})$, radiação solar global $\left(\mathrm{W} / \mathrm{m}^{2}\right)$, radiação líquida $\left(\mathrm{W} / \mathrm{m}^{2}\right)$, radiação fotosinteticamente ativa, direção e velocidade do vento, temperatura do $\operatorname{ar}\left({ }^{\circ} \mathrm{C}\right)$ e umidade relativa do ar (\%), em intervalos horários. Os dados são transmitidos diariamente via rádio ao escritório, para análise de consistência e armazenamento.

Foram instalados e medidos dois experimentos de interceptação de precipitação pluviométrica, sendo um no interior do plantio de eucalipto e outro na floresta nativa. Cada experimento continha 25 pluviômetros convencionais e dois automáticos, distribuídos aleatoriamente em uma área de $625 \mathrm{~m}^{2}$. Após um dado evento de chuva, os pluviômetros eram trocados de posição com base em pontos distantes 1 metro entre sí.. Foram ainda instalados coletores para medição da água que escorre pelos troncos das árvores. Este experimento foi conduzido na área de eucalipto no período de 1995 a 1996 e de 1997 a 1998 e na floresta nativa de 1995 à 1998; atualmente somente os pluviômetros automáticos acima e abaixo do dossel estão mantidos.

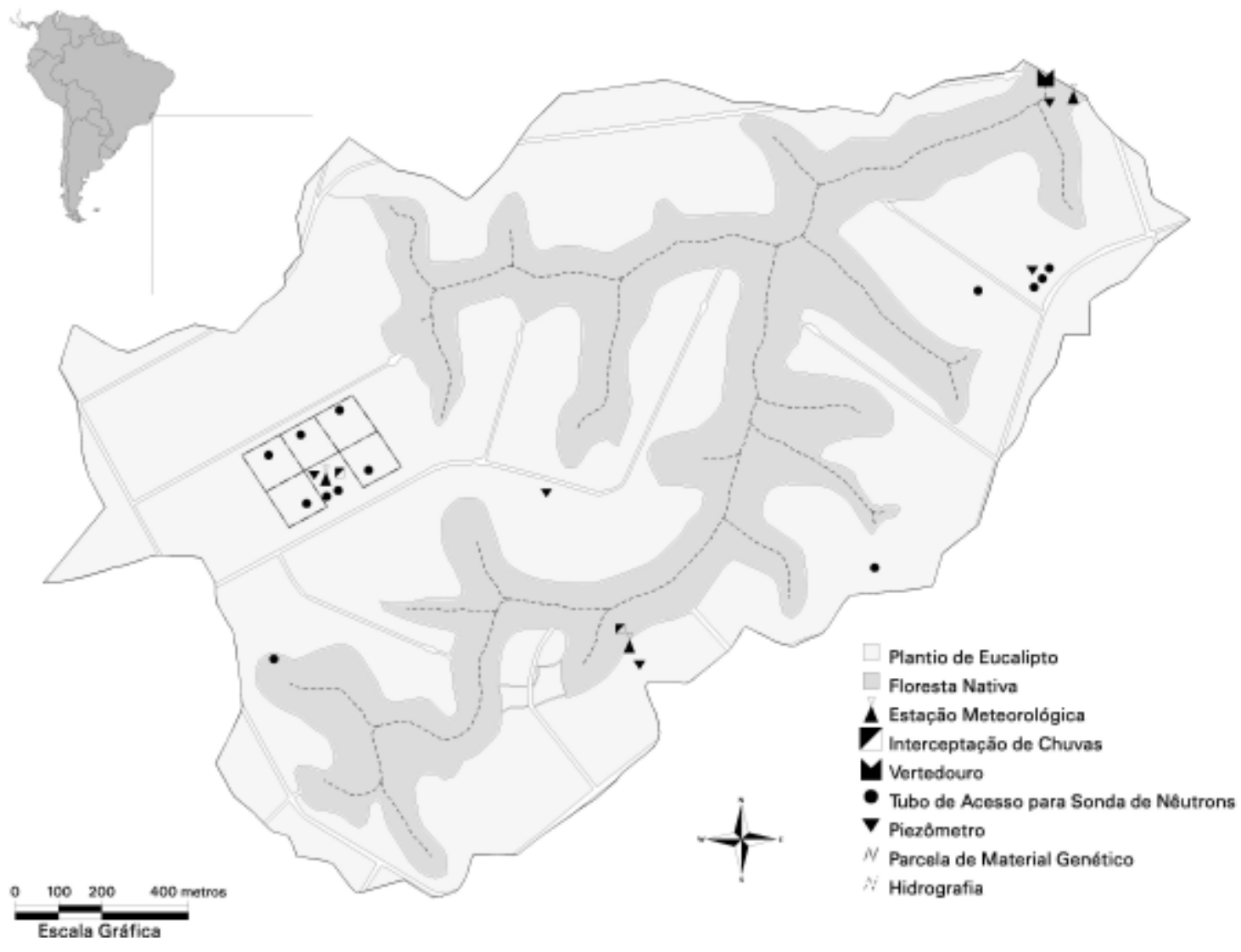

Figura 2 - Mapa da microbacia contendo os experimentos hidrológicos. Figure 2 - Watershed map indicating the hydrologic study sites. 
Para medição de umidade do solo, foram instalados 13 tubos de acesso de sonda de nêutrons. As estimativas são realizadas semanalmente nos períodos de chuva e quinzenalmente nos meses mais secos, a cada $20 \mathrm{~cm}$, até uma profundidade de $3 \mathrm{~m}$ (três tubos até a profundidade de $6 \mathrm{~m}$ ). Um vertedouro na saída da bacia (Figura 2), aparelhado com linígrafo, realiza medições da altura da lâmina d'água (e a vazão correspondente) que escoa para fora da bacia, a cada 5 minutos.

São realizadas mensalmente medições de índice de área foliar com o aparelho ótico LICOR 2000 (método da atenuação luminosa pelo dossel), previamente calibrado com valores de $I A F$ determinados por amostras destrutivas de árvores. Detalhes sobre o método nãodestrutivo utilizado para estimar o IAF pode ser encontrado em Xavier et al.(2002). Foram também conduzidas campanhas ecofisiológicas para medição de condutância estomática e potencial hídrico foliar tanto em períodos de seca prolongada como de alta disponibilidade hídrica. Também são realizados anualmente procedimentos para quantificação de biomassa, incluindo massa e distribuição de raízes por amostragem destrutiva de árvores de eucalipto de diferentes materiais genéticos.

A MBE está na quarta rotação de plantio de eucalipto, tendo o plantio atual sido concluído em janeiro de 1997. A rotação anterior foi cortada entre os meses de setembro a outubro de 1996. Atualmente, o período médio da rotação é próximo de 7 anos.

Neste trabalho, discute-se inicialmente a resposta da condutância estomática do eucalipto à disponibilidade hídrica na zona radicular do solo. Na seqüência, na avaliação comparativa dos comportamentos hidrológicos das plantações de eucalipto com a Mata Atlântica, são comparados a interceptação pelo dossel; a água disponível no solo obtida por sonda de nêutrons; o ajuste do modelo UAPE (comparando água disponível estimada pelo modelo às medidas de campo para o ano hidrológico 1995/1996, último ano antes do corte do ciclo anterior); e a relação evapotranspiração/precipitação para vários anos hidrológicos*, incluindo 1995/1996 (9 anos de idade), 1998/1999 (2-3 anos), 1999/2000 (3-4 anos) e 2000/2001 (5-6 anos), integrando diferentes fases do ciclo produtivo do eucalipto. São também discutidas a vazão de saída no vertedouro e a relação entre a oferta de energia e a transpiração do eucalipto para um ano hidrológico representativo do clima da região.

* Ano hidrológico vai de outubro (início da estação chuvosa) a setembro (final da estação seca).

R. Árvore, Viçosa-MG, v.27, n.2, p.159-170, 2003

\section{RESULTADOS E DISCUSSÃO}

A Figura 3 sintetiza as variações temporais da condutância estomática máxima $\left(g_{s} \max , \mathrm{m} / \mathrm{s}\right.$, que ocorrem em torno da metade do período matinal) e do potencial de água na folha ao amanhecer $\left(\Psi_{1}, M P a\right)$, obtidos nos experimentos de ecofisiologia da MBE nos plantios de eucalipto no período de setembro 1995 a agosto 1996. Esta figura deve ser analisada em conjunto com a Figura 5 , que mostra o curso da água disponível no solo. Constata-se que enquanto $\Psi_{1}$ permanece entre 0,4 e $0,6 \mathrm{MPa}$ de outubro de 1995 a maio de 1996, a condutância estomática situa-se em torno de $0,01 \mathrm{~m} / \mathrm{s}$. Entretanto, a partir de junho 1996, quando o estoque de água cai para menos de $30 \%$ da capacidade de retenção de água do solo, os valores de $\Psi_{1}$ decrescem para menos de $-1,0 \mathrm{MPa}$ e a condutância estomática diminui sensivelmente, atingindo valores abaixo de $0,004 \mathrm{~m} / \mathrm{s}$. Estes resultados demonstram claramente que o eucalipto exerce controle estomático eficiente em condições de suprimento limitado de água no solo.

Os dados de interceptação pluviométrica da floresta nativa e do eucalipto durante o período de setembro de 1995 a setembro de 1996 estão na Figura 4. Do total de chuvas sobre a Mata Atlântica, aproximadamente 24\% foi interceptado $(0,0013 \mathrm{~m} / \mathrm{IAF} / \mathrm{dia})$, montante normalmente reevaporado sem atingir o complexo mineral do solo, enquanto para o eucalipto este valor foi próximo de $11 \%$ da precipitação (0,0004 m/IAF/dia). Estes dados devem ser analisados em conjunto com os dados de IAF

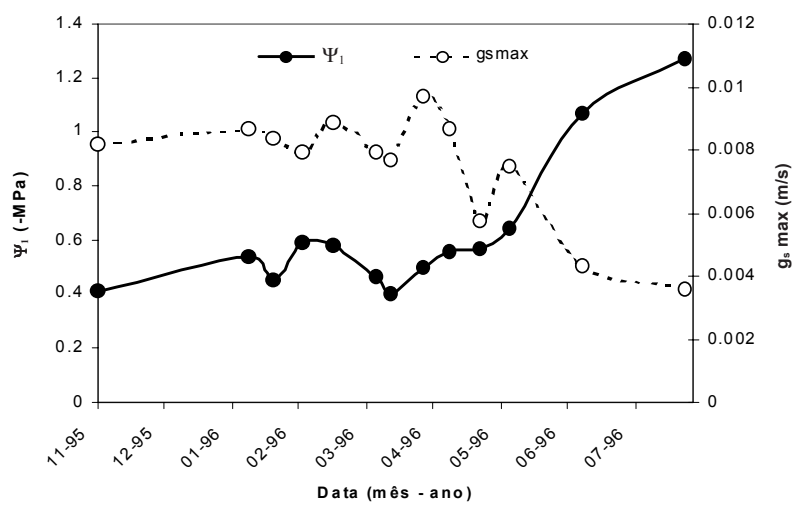

Figura 3 - Variação temporal da condutância estomática $\left(\mathrm{g}_{\text {smax }}, \mathrm{m} / \mathrm{s}\right)$ e potencial de água na folha ao amanhecer $\Psi_{1}$ $(-\mathrm{MPa})$, de Mielke et al (1999).

Figure 3 - Time variation of stomata conductance $\left(g_{\text {smax }}, \mathrm{m} / \mathrm{s}\right)$ and predawn $\Psi_{1}(-\mathrm{MPa})$, from Mielke et al. (1999). 


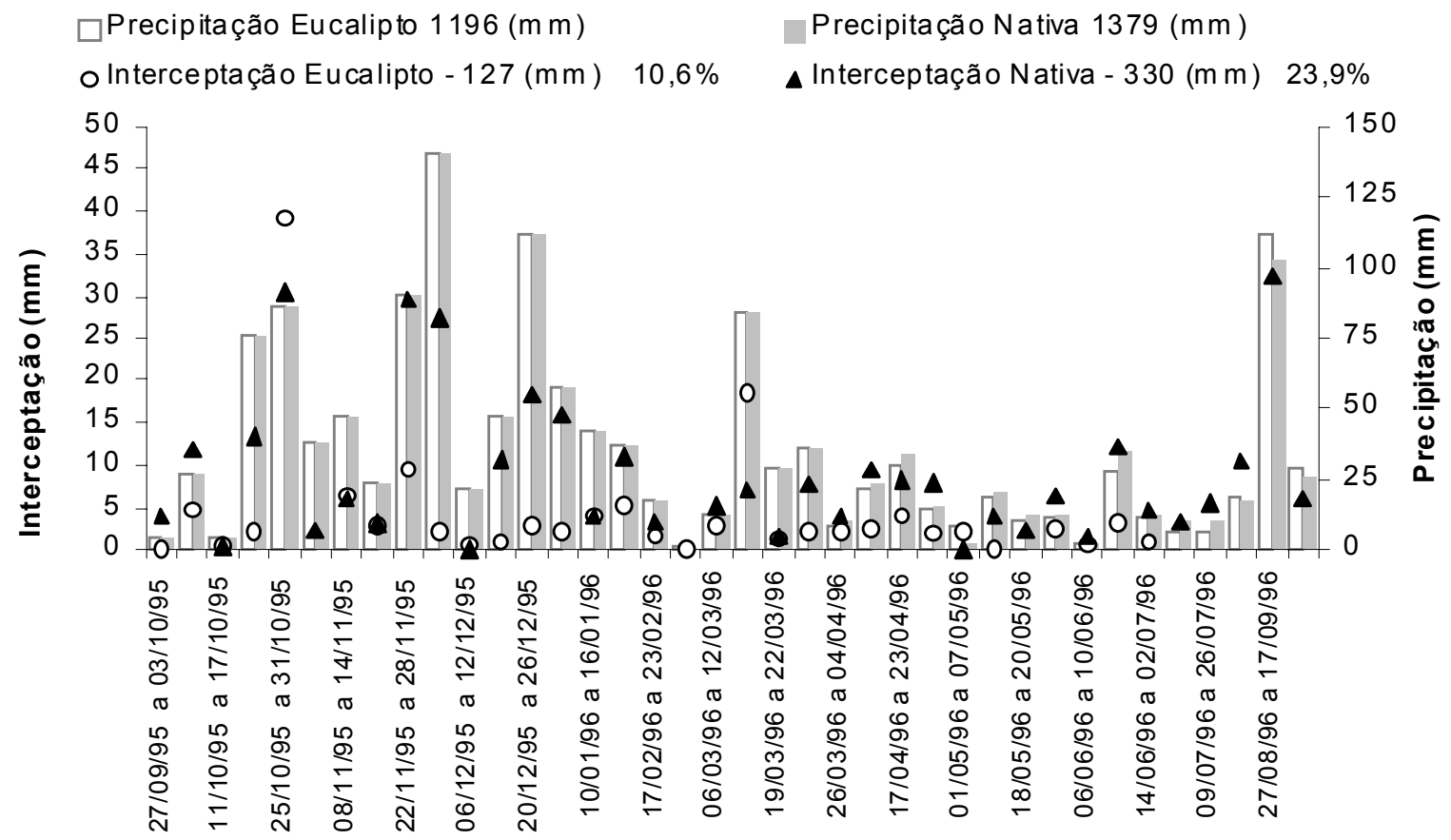

Figura 4 - Interceptação da precipitação pluviométrica medida na floresta nativa e na plantação de eucalipto durante o período de setembro de 1995 a setembro de 1996.

Figure 4-Measured precipitation interception in native forest and eucalypt plantation from September 1995 to September 1996.

para o eucalipto e para a mata nativa (Figura 7), os quais indicam que o IAF da Mata Atlântica é o dobro do IAF da plantação de eucalipto. Valores similares de interceptação de eucalipto foram encontrados por Prebble \& Stirk (1980) para árvores de Eucalyptus melanophloia, na Austrália. Os valores de interceptação da mata nativa mostraram-se superiores aos da Amazônia, obtidos por Uburana (1996), que são 11,6 e 12,9 \% para a Reserva Jaru (Ji-Paraná, Rondônia) e a Reserva Vale do Rio Doce (Marabá, Pará). Entretanto, os valores destes autores são resultados de um período de coleta com mais de $3.500 \mathrm{~mm}$ de precipitação, e deve-se sempre ter em mente que a fração de interceptação é menor para maiores intensidades de chuva (Soares \& Almeida, 2001; Uburana, 1996).

A Figura 5 mostra uma comparação entre a variação dos estoques de água disponível no solo até $2,5 \mathrm{~m}$ de profundidade, para a plantação de eucalipto e a floresta nativa, ao longo de um período de 29 meses de coleta semanal ou quinzenal, entre novembro de 1999 e março de 2002. Observa-se que, em geral, as variações dos estoques seguem não apenas tendências muito semelhantes, como também indicam taxas de retirada de água do sistema radicular praticamente iguais em períodos de grande disponibilidade hídrica e oferta energética, que ocorrem nos meses de verão. A absorção de água na zona de atuação das raízes resulta principalmente da transpiração. É uma indicação clara que os dois ecossistemas possuem taxas de transpiração muito próximas, nas condições do estudo. No inverno (de julho a setembro de 2000), em meses de menor aporte energético, os estoques de água no eucalipto atingem valores mais baixos, o que parece refletir o fato de o sistema radicular das árvores emergentes da mata nativa atingir $5 \mathrm{~m}$ ou mais, podendo, conseqüentemente, estar absorvendo água em profundidades maiores no solo, além de estar nos declives da drenagem da bacia em uma zona mais úmida. Entretanto, no verão-outono de 2001, o decréscimo dos estoques de água no solo foi praticamente idêntico nos dois casos, o que poderia ser atribuído ao fato de ter chovido menos neste período que no ano anterior $(1.000 \mathrm{~mm}$ versus $1.300 \mathrm{~mm}$, Figura 8). A Figura 5 indica também que os valores residuais de água disponível no solo sob plantações de eucalipto são de cerca de 15 a $20 \%$ dos valores da capacidade de retenção $(200 \mathrm{~mm}$ para os 2,5 primeiros metros).

R. Árvore, Viçosa-MG, v.27, n.2, p.159-170, 2003 


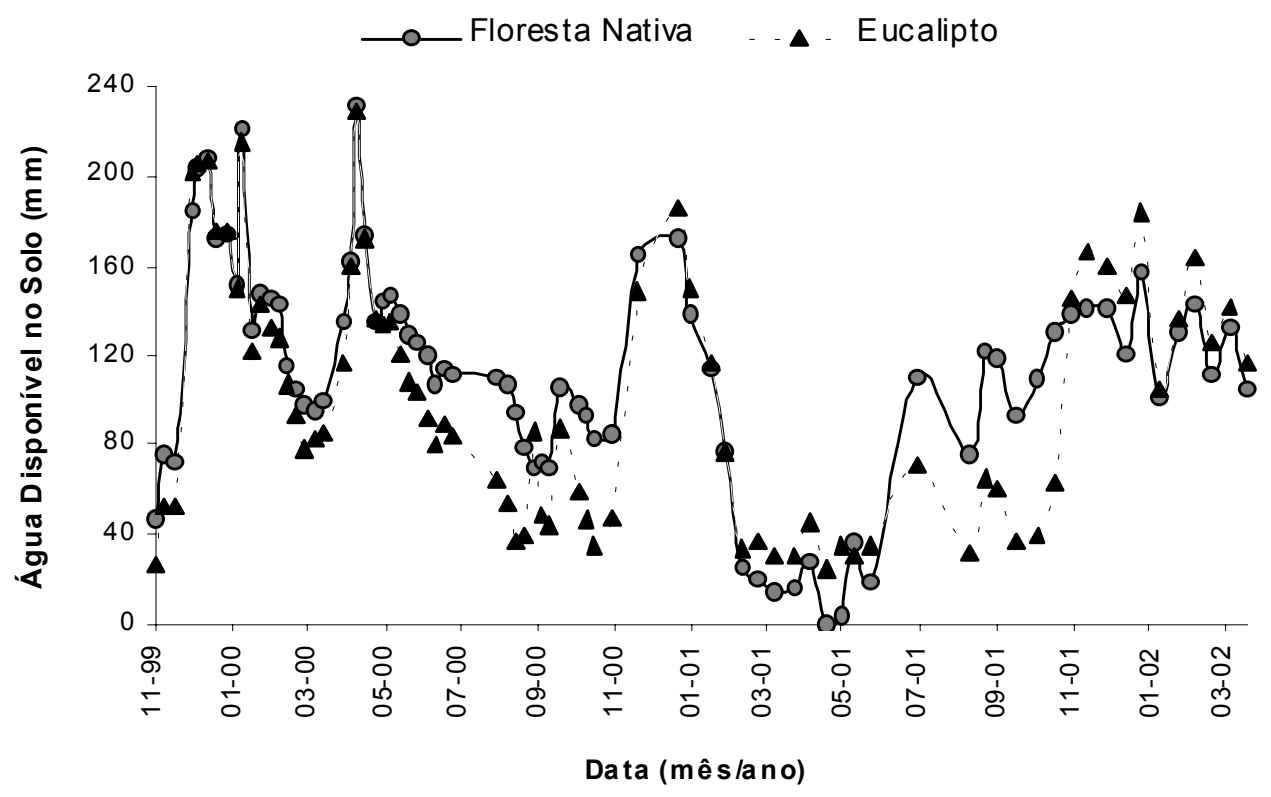

Figura 5 - Medição de água disponível no solo, comparação entre floresta nativa e plantação de eucalipto para um período de 29 meses, entre novembro 1999 a março 2002.

Figure 5 - Measured available water in soil, comparison between native forest and eucalypt plantation during 29 months, from November 1999 to March 2002.

A Figura 6 representa o ajuste do modelo uso de água em plantações de eucalipto, UAPE, através da comparação entre os valores umidade do solo (água disponível, $\mathrm{mm}$ ) medidos e estimados pelo modelo para o ano hidrológico 1995/1996. Em geral a concordância entre os valores é excelente. Foram constatadas taxas praticamente idênticas de redução da umidade do solo ao longo do mês de janeiro, caracterizado por um veranico ocorrido depois de $770 \mathrm{~mm}$ de precipitação nos meses precedentes, o que levou o solo à sua capacidade de estoque. De abril até meados de setembro (período seco, outono/inverno) os valores calculados pelo modelo foram muito próximos aos medidos; durante o mês de agosto o acordo foi praticamente perfeito, indicando a ocorrência de um fluxo de água ascendente para a camada de solo que compreende o sistema radicular, o que permite manter a transpiração em aproximadamente $20 \%$ do potencial e os estoques de água em aproximadamente 15\% da capacidade de retenção (Soares \& Almeida, 2001).

Na Figura 7 estão os valores de IAF para os dois ecossistemas. O plantio de eucalipto no ciclo atual foi concluído em janeiro de 1997. Os valores de IAF para o eucalipto atingem o máximo de 3,5 entre 3 e 4 anos de idade, com um declínio sazonal que pode chegar a 35\% nos meses de inverno. A relação 2:1 entre IAF Mata Atlântica e IAF eucalipto está claramente representada. Dye (1987) obteve valores de IAF de 4,2 para plantações de Eucalyptus grandis na África do Sul, com densidade de 725 árvores/ha após desbaste e medidas em torno de 3,0 para plantações de 3 anos (Eucalyptus grandis W.Hill ex Maiden) sem desbaste. Os valores de IAF medidos aqui para a Mata Atlântica são também superiores aos obtidos por Roberts et al. (1996) e McWilliam et al. (1993) na Reserva Ducke em Manaus, de 6,1 e $5,7 \mathrm{~m}^{2} / \mathrm{m}^{2}$, respectivamente. Do ponto de vista hidrológico, é importante salientar que embora a transpiração seja positivamente correlacionada com IAF, a atenuação da radiação a partir do topo da copa para as partes inferiores do dossel (lei de Beer) torna a condutância global do dossel de várias espécies florestais muito próximas para valores de IAF superiores a 3,0 (Kelliher et al., 1995). Segundo estes autores o nível de radiação nas camadas foliares mais baixas é muitas vezes inferior ao limiar de radiação para pleno funcionamento fisiológico (abertura dos estômatos). Por outro lado, como já discutido, o aumento do IAF implica uma maior interceptação e re-evaporação de água pela folhagem. 


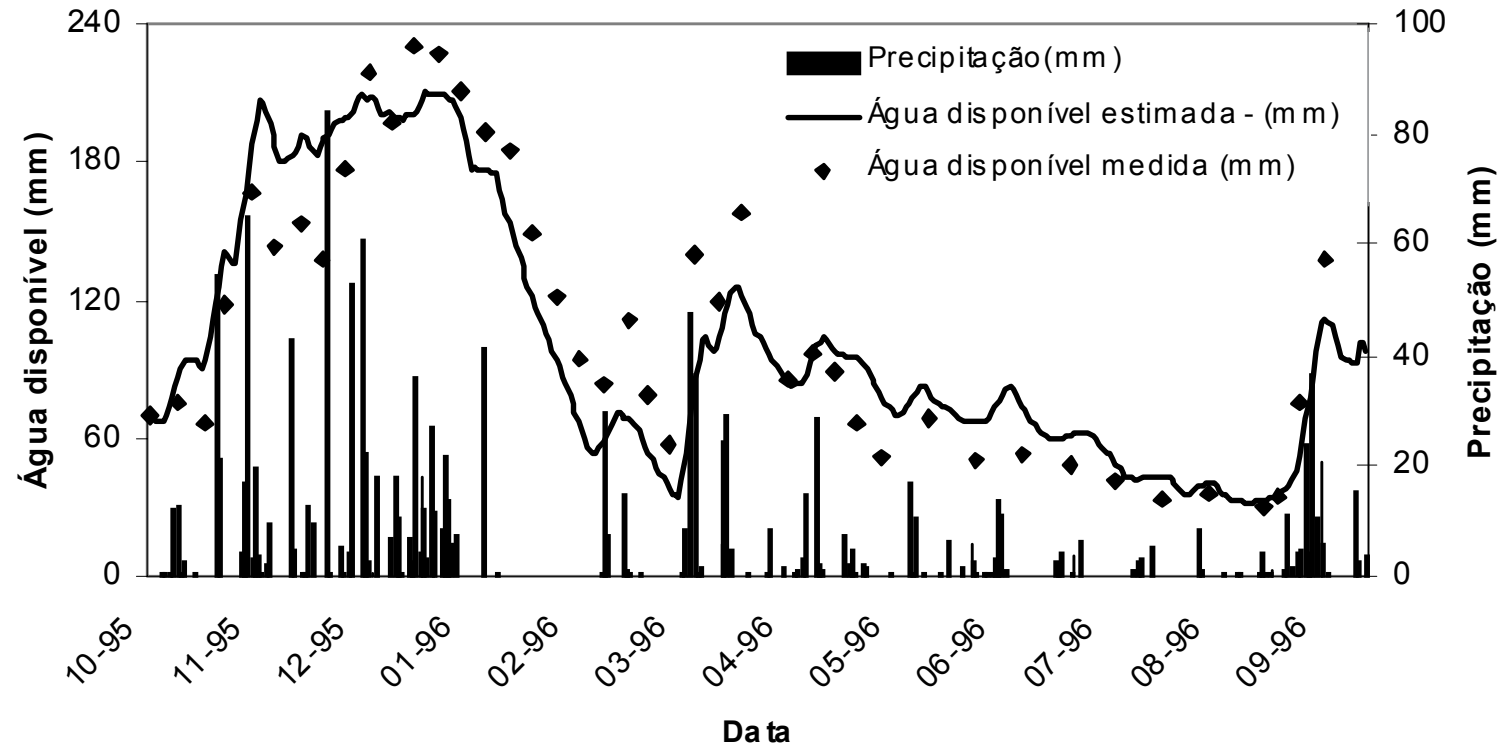

Figura 6 - Água disponível estimada (linha sólida) x água disponível medida na zona radicular, para o ano hidrológico outubro/95 - setembro/96 e precipitação pluviométrica diária. Adaptado de Soares \& Almeida (2001).

Figure 6 - Estimated available soil water x measured available soil water, for the period from October 1995 to September 1996 and daily precipitation. Adapted from Soares \& Almeida (2001).

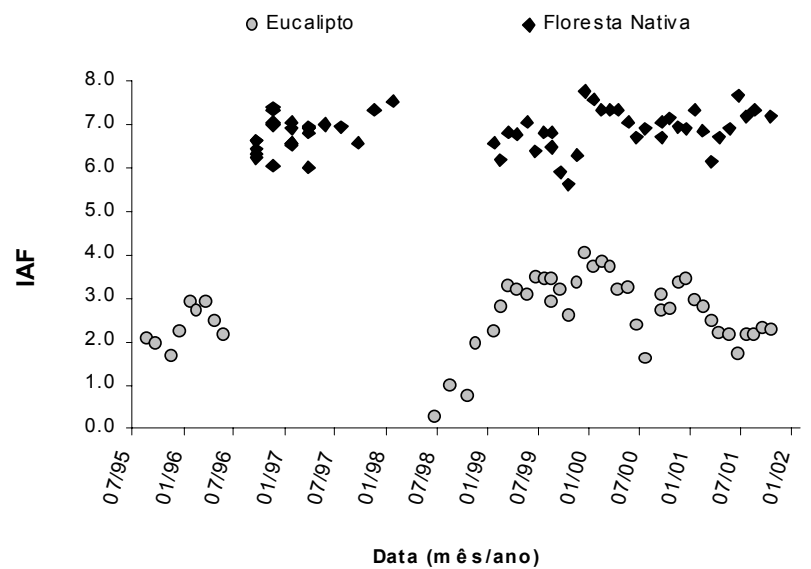

Figura 7 - Índice de área foliar na floresta nativa e no plantio de eucalipto. A plantação de eucalipto foi cortada em setembro de 1996 e um novo plantio foi realizado em janeiro de 1997.

Figure 7 - Leaf area index in native forest and eucalypt plantation. The eucalypt plantation was harvested in September 1996 and a new plantation was established in January 1997.

A Figura 8 sintetiza e permite a comparação dos comportamentos hidrológicos de plantações de eucalipto e mata nativa, através da relação evapotranspiração-precipitação para os anos hidrológicos 1995/1996 (último ano antes do corte, eucalipto excepcionalmente com 9 anos de idade), 1998/1999 (2-3 anos), 1999/2000
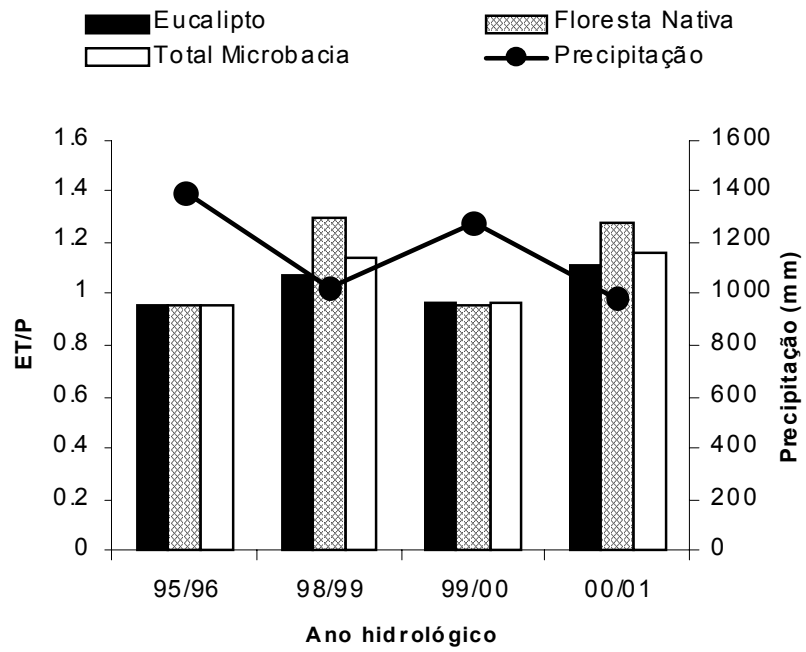

Figura 8 - Relação entre evapotranspiração e precipitação pluviométrica na plantação de eucalipto e na floresta nativa e total ponderado na microbacia. A precipitação pluviométrica total ocorrida em cada ano hidrológico estudado está apresentada no eixo da direita.

Figure 8 - Relation between evapotranspiration and precipitation in eucalypt plantation, native forest and the total integrated in the watershed. The annual precipitation is presented (right axis).

R. Árvore, Viçosa-MG, v.27, n.2, p.159-1 70, 2003 
(3-4 anos) e 2000/2001 (5-6 anos). A evapotranspiração é a soma dos componentes de transpiração, evaporação do solo e reevaporação da água interceptada. A análise integra diferentes idades do eucalipto, o que permite comparações, considerando o ciclo produtivo da plantação. A normalização do uso consuntivo de água (evapotranspiração) pela oferta (precipitação) é uma maneira de minimizar o efeito da variabilidade hidrometeorológica interanual sobre o comportamento hidrológico dos dois ecossistemas sob análise. Verifica-se que existem dois anos de precipitação próxima à média histórica de $1.375 \mathrm{~mm}$ para a região, que são 1995/1996, com $1.396 \mathrm{~mm}$, e 1999/2000, com $1.230 \mathrm{~mm}$, e dois anos de baixa precipitação pluviométrica em torno de $1.000 \mathrm{~mm}$ para os anos hidrológicos 1998/99 e 2000/2001. A razão ET/P varia no sentido inverso, ou seja, é maior para anos de baixa oferta de água pela chuva. Para anos em que as normais climatológicas são verificadas como em 1995/1996 e 1999/2000, a razão entre ET e P é praticamente unitária, o que significa que os dois ecossistemas têm seus suprimentos de água garantidos pela precipitação atmosférica. Deve-se destacar que os dois sistemas possuem taxas de evapotranspiração praticamente idênticas quando o eucalipto está no final de seu ciclo de crescimento (que neste caso foi de 9 anos para o estabelecimento da MBE, quando normalmente o corte se dá aos 7 anos). Para os anos hidrológicos mais secos, como os de 1998/1999 e 2000/2001, a relação ET/P é superior a 1 , indicando que os sistemas usam reservas hídricas do solo para suprir suas demandas de crescimento. Todavia, nestes casos, a floresta nativa apresentou valores da relação ET/P superiores aos da plantação de eucalipto, nos dois períodos, ainda que no ano 1998/1999 a diferença tenha sido mais acentuada, 1,27 versus 1,12 (13\%) e 1,25 versus $1,15(8 \%)$. A diferença maior para o ano 1998/1999 está associada ao fato de a plantação de eucalipto ser ainda relativamente jovem, com idade média de 27 meses no período. No ano seguinte, com boa oferta hídrica e o eucalipto entre 3 e 4 anos, os dois sistemas mostraram comportamentos hidrológicos

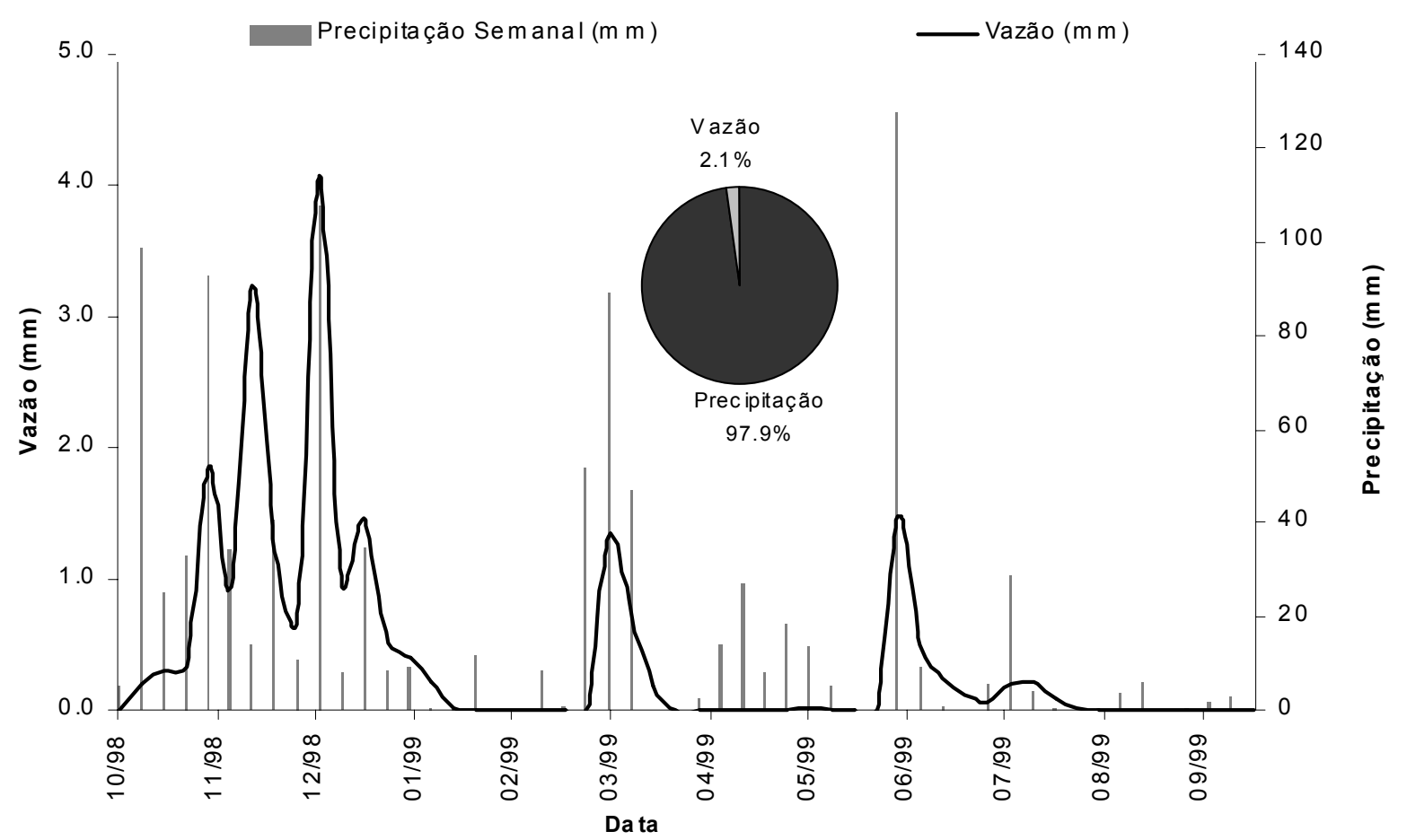

Figura 9 - Vazão semanal (normalizada para a área da bacia) medida no vertedouro da MBE durante o ano hidrológico de 1998/ 1999 (eixo esquerda) e precipitação semanal (eixo direita). O círculo apresenta o porcentual escoado no período em relação ao total precipitado na bacia.

Figure 9-Measured weekly runoff in the experimental watershed area, during the hydrologic year of 1998/1999 (left axis) and weekly precipitation (right axis). The circle presents the runoff percentage in relation to the total precipitation in the watershed. 
praticamente idênticos. No ano 2000/2001, a diferença de $8 \%$ foi devido à maior interceptação pela mata nativa. Sintetizando a informação apresentada nessa figura, podese argumentar que ao longo do ciclo de crescimento da plantação de eucalipto a floresta nativa pode ter uso consuntivo de água maior que o do eucalipto, dado que nos primeiros anos do ciclo a transpiração das plantações é menor que a da mata nativa. A evapotranspiração da mata nativa, da ordem de $1.350 \mathrm{~mm} / \mathrm{ano}$, foi muito próxima dos valores medidos por correlação de vórtices e estimados pelo modelo SiB2 por da Rocha et al. (1996), para três sítios experimentais na Amazônia, no projeto ABRACOS (Reserva Ducke, 1.354; Reserva Jaru, 1.354; e Reserva Vale do Rio Doce, $1.450 \mathrm{~mm}$ anuais).

A Figura 9 mostra o comportamento da vazão no vertedouro da microbacia, normalizada para a área total da bacia, e sua associação com a precipitação medida no período fevereiro-julho de 1997 (após o corte raso), quando o vertedouro entrou em fase operacional. Uma análise "in loco" mostra que os picos de vazão são uma resposta rápida aos eventos de precipitação. É um indicativo de que a precipitação direta nos canais de drenagem é a principal fonte de água para o reservatório do vertedouro. Outra fonte seria o escoamento subsuperficial das áreas das vertentes mais próximas da drenagem. No ano de 1998 (janeiro - dezembro) saíram pelo vertedouro cerca de $45 \mathrm{~mm}$ de água (vazão totalizada $\mathrm{em}^{3}$ dividida pela área da microbacia experimental), o que corresponde a apenas 3\% do total precipitado. Destes 3\% estima-se que a metade seja precipitação direta nos canais e a outra metade seria de escoamento subsuperficial da vizinhança da rede de drenagem. Portanto, a vazão de saída da bacia é um componente quase negligenciável do balanço de água, o que reforça as conclusões sobre o equilíbrio entre evapotranspiração e precipitação.

\section{CONCLUSÕES}

O estudo permitiu concluir que as plantações de eucalipto (E. grandis) exercem controle estomático eficiente em condições de baixa disponibilidade de água no solo. As medidas de campo, bem como as estimativas realizadas a partir dos modelos, revelaram que as plantações de eucalipto se comparam à Mata Atlântica quanto à evapotranspiração e ao uso de água do solo. Considerando o ciclo de crescimento como um todo (cerca de 7 anos), o eucalipto pode consumir menos água que a mata nativa na região estudada. Em anos de precipitação em torno dos valores médios das normais climatológicas, ocorre equilíbrio entre oferta (precipitação) e demanda (evapotranspiração) para os dois ecossistemas. Em anos de menor precipitação, as reservas hídricas do solo são utilizadas tanto para o eucalipto quanto para a Mata Atlântica. A Mata Atlântica apresentou taxas de evapotranspiração muito próximas às obtidas para a Região Amazônica.

\section{AGRADECIMENTO}

À Aracruz Celulose S.A., pela autorização da divulgação dos resultados deste estudo, e à equipe de engenheiros e técnicos da empresa que participam ativamente nas medições e coletas de dados no Projeto Microbacia da Aracruz, disponível no site www.aracruz.com.br.

\section{REFERÊNCIAS BIBLIOGRÁFICAS}

ALBUQUERQUE, J. L. F. et al. Caracterização geológica de microbacia de monitoramento ambiental com o uso de métodos geofísicos. Aracruz, ES: 1997.

CAMPBELL, G. S. A simple method for determining unsaturated conductivity from moisture retention data. Soil Science, v. 117, p. 311-314, 1974.

CHOUDHURY, B. J.; MONTEITH, J. L. A four-layer model for the heat budget of homogeneous land surfaces. Quarterly Journal of the Royal Meteorological Society, v. 114, p. $373-398,1988$.

CLAPP, R. B.; HORNBERGER, G. M. Empirical equations for some soil hydraulic properties. Water Resources Research, v. 14, n. 4, 1978.

DYE, P. J. Response of Eucalyptus grandis trees to soil water deficits. Tree Physiology, v. 16, p. 233-238, 1996.

DYE, P. J. Estimating water use by Eucalyptus grandis with the Penman-Monteith equation. Vancouver, Canada.

Anais... Vancouver, Canada: International Association of Hydrological Sciences, 1987. p. 329-337.

HEWLLET, J. D. Principles of forest hydrology. Athens, EUA: The University of Georgia Press, 1982. 183 p.

INSTITUTO BRASILEIRO DE GEOGRAFIA E ESTATÍSTICA - IBGE. IBGE teen. [online] Disponível em $<$ http://www.ibge.gov.br/ibgeteen/default.htm>. Acessado em 29/08/2002.

R. Árvore, Viçosa-MG, v.27, n.2, p.159-1 70, 2003 
KELLIHER, F. M. et al. Maximum conductances for evaporation from global vegetation types. Agricultural and Forest Meteorology, v. 73, p. 1-16, 1995.

LANDSBERG, J. J. Tree water use and its implications in relation to agroforestry systems. In: LANDSBERG, J. J. (Ed.) The ways trees use water. ACT: Rural Industries Research and Development Corporation, 1999. p. 1-38.

McWILLIAM, A. L. C. et al. Forest and pasture leaf-gas exchange in south-west Amazonia. In: GASH, J. H. C. et al. (Eds.) Amazonian deforestation and climate. Chichester: John Wiley \& Sons, 1996. p. 265-286.

McWILLIAM, A. L. C. et al. Leaf area index and aboveground biomass of terra firme rain forest. Functional Ecology, v. 7, p. 310-317, 1993.

MIELKE, M. S. et al. Stomatal control of transpiration in the canopy of a clonal Eucalyptus grandis plantation.

Trees, v. 13, p. 152-160, 1999.

PREBBLE, R. E.; STIRK, G. B. Throughfall and stemflow on silverleaf ironbark (Eucalyptus melanophloia) trees.

Australian Journal of Ecology, v. 5, p. 419-427, 1980.

ROBERTS, J. M. et al. An overview of the leaf area index and physiological measurememts during ABRACOS. In: GASH, J. H. C. et al. (Eds.) Amazonian deforestation and climate. Chichester: John Wiley \& Sons, 1996. p. 287-306.

ROCHA, H. R. et al. Calibration and use of the SiB2 model to estimate water vapour and carbon exchange at the ABRACOS forest sites. In: GASH, J. H. C. et al. (Eds.) Amazonian deforestation and climate. Chichester: John Wiley \& Sons, 1996. p. 459-472.
RUNNING, S. W.; COUGHLAN, J. C. A general model of forest ecosystem processes for regional applications I. Hydrologic balance, canopy gas exchange and primary production processes. Ecological Modelling, v. 42, p. 125154, 1988.

SOCIEDADE BRASILEIRA DE SOLOS - SBS. Área plantada com pinus e eucaliptos no Brasil (ha) - 2000. [online] Disponível em $<$ http://www.sbs.org.br/ area_plantada.htm $>$. Acessado em 20/06/2001

SOARES, J. V.; ALMEIDA, A. C. Modeling the water balance and soil water fluxes in a fast growing Eucalyptus plantation in Brazil. Journal of Hydrology, v. 253, p. 130$147,2001$.

SOMMER, R. et al. Transpiration and canopy conductance of secondary vegetation in the eastern Amazon.

Agricultural and Forest Meteorology, v. 112, n. 2, p. 103121, 2002.

UBURANA, V. N. Observations and modelling of rainfall interception at two experimental sites in Amazonia. In: GASH, J. H. C. et al. (Eds.) Amazonian Deforestation and Climate, West Sussex, U.K.: John Willey \& Sons, 1996. p. 151-162.

WARING, R. H.; RUNNING, S. W. Forest ecosystems: analysis at multiple scales. San Diego: Academic Press, 1998. $370 \mathrm{p}$.

XAVIER, A. C.; SOARES, J. V.; ALMEIDA, A. C. Variação do índice de área foliar em clones de eucalipto ao longo do seu ciclo de crescimento. Revista Árvore, v. 26, n. 4, p. 421- 427, 2002. 